\title{
Location of the mandibular foramen-Radiographic s
}

\author{
Nazar Gh JAMEEL*
}

\begin{abstract}
A comparison between the location of mandibular foramen on ten dry mandibles has been used in this study with its location on the two extraoral radiographic projections taken for each dry mandible. First projection with the use of panoramic radiograph and the second projection have been taken by lateral oblique jaw projection. The results are shown no significant difference between the measurements are taken from both radiographs. But still the lateral oblique jaw radiograph is more resoluted and accurate in the localization of the mandibular foramen.
\end{abstract}

Key Worls: Mandiubular foramen, location, extraoral radiographic projection.

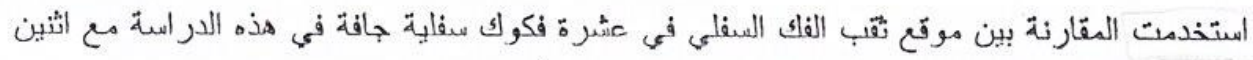

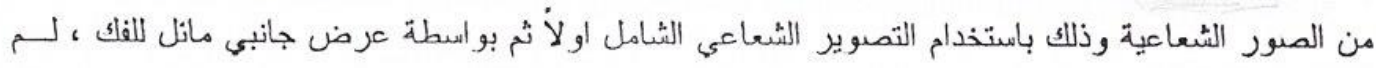

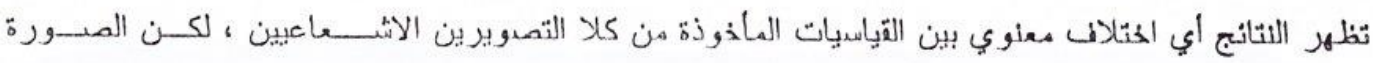

الشعاعية للفك الجانبي المانل هي اكثر دقة في تحديد موقع نقب الفك السفلي .

\section{INTRODUCTION}

The precise location of the mandibular foramen is essential in dentistry for effective inferior alveolar nerve block anesthesia ${ }^{(1)}$, where its administered routinely in dental practice, it is not universally successful ${ }^{(2)}$, The most common cause of failure in this anesthetic procedure is improper placement of hypodermic needle because of improper evaluation of anatomic land marks ${ }^{(3)}$. For other procedures in oral and maxillofacial surgery in such cases, the failure to determine the precise location of mandibular foramen may lead to hemorrhage and permanent neurologic damage caused by transsection of the inferior alveolar neuromuscular bundle that enters the mandibular canal at the mandibular foramen ${ }^{(4)}$.

Radiography is only the available non-invasive methods for diagnosis and treatment planning of major surgical procedures of the mandible ${ }^{(1)}$.

The objectives of our study are to localize the mandibular foramen by means of panoramic and lateral oblique of the jaw radiography in comparison with actual location of the mandibular foramen.

*Nazar Ghanem JAMEEL; BDS, MSc: Lecturer. Department of Oral and Maxillofacial Surgery, College of Dentistry, University of Mosul, Mosul, IRAQ. 


\section{MATERIALS AND METIIODS}

Ten dry mandibles have been used for this study, a metalic ball are fixed on the location of mandibular foramen in order to increase the contrast of the foramen in the produced radiographs to facilitate our measurements.

All mandibles have been radiographed with the use of panoramic $x$-ray machine type Orthopantomography 10-E from (siemens Corp.-Germany) operated at (60) kvp. \& (9) $\mathrm{mA}$., with the use of Palmex high speed screen cassette (figure 1). The other radiograph have been made for the same mandible with use of Marksman-II $x$-ray machine from (Wehmer Franklin ParkU.S.A) operated at (90) kvp., (15) $\mathrm{mA}$ \& (40) impulses to take lateral oblique jaw projection (figure 2).

The following anatomic sites are used as reference points;

(1) The distance from the mandibular foramen to the deepest point of the most anterior border of ascending ramus of the mandible.

(2) The distance between the mandibular foramen and the highest point of the outer surface of the head of the condyle.

(3) The distance between the mandibular foramen and the angle of the mandible (figure 3).

Data have been evaluated from the dry mandible and the two radiographs to study the possibility of accurately predicting the actual location of mandibular foramen and its distance from the anterior border of ascending ramus of the mandible, angle of the mandible and outer surface of the condyle, by comparison between the accuracy of measurements from panoramic radiograph and lateral oblique jaw projection with actual measurements are taken from the dry normal mandibles.

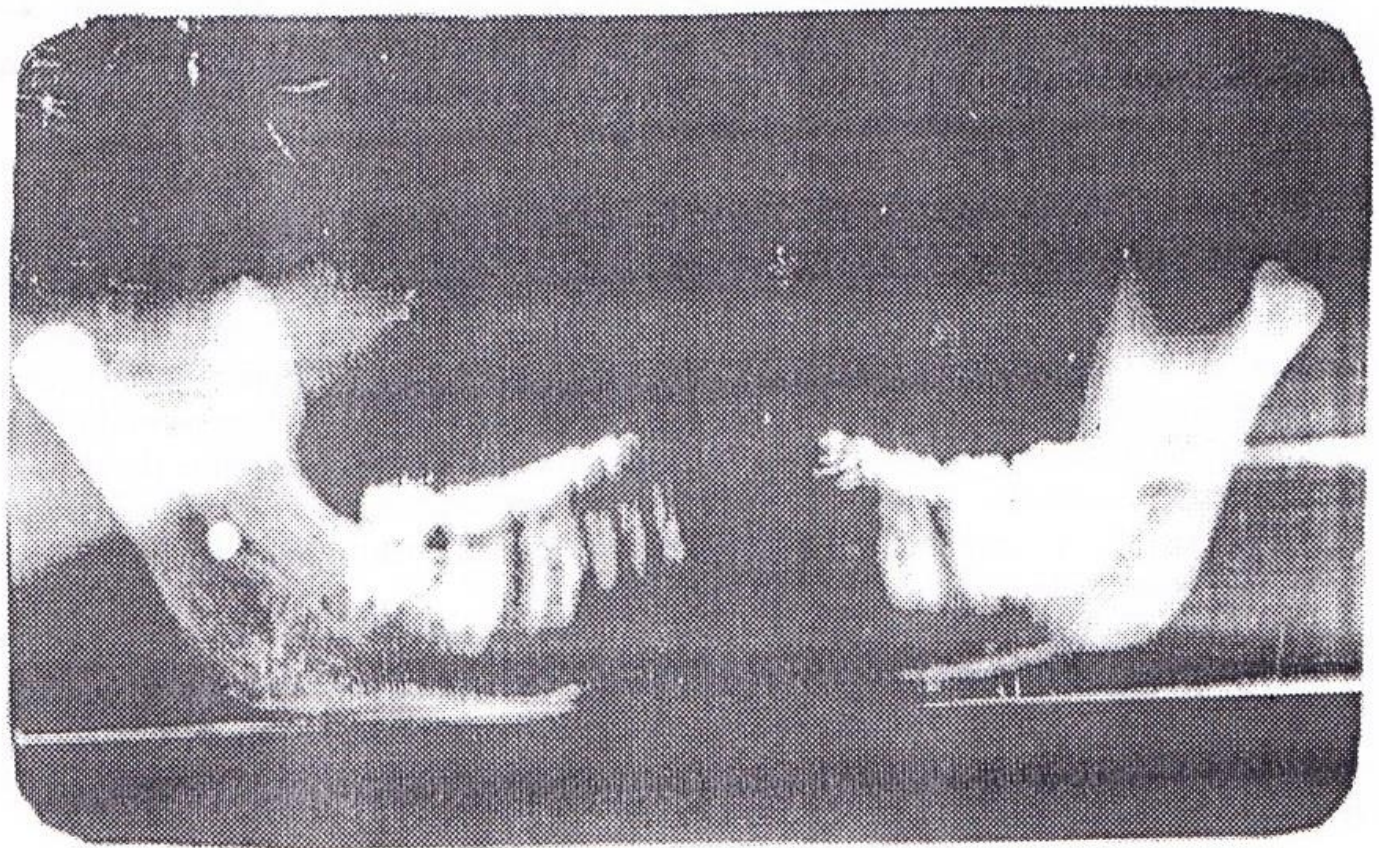

Figure (1): Panoramic radiograph for the dry mandible with the metallic ball on the position of mandibular foramen 


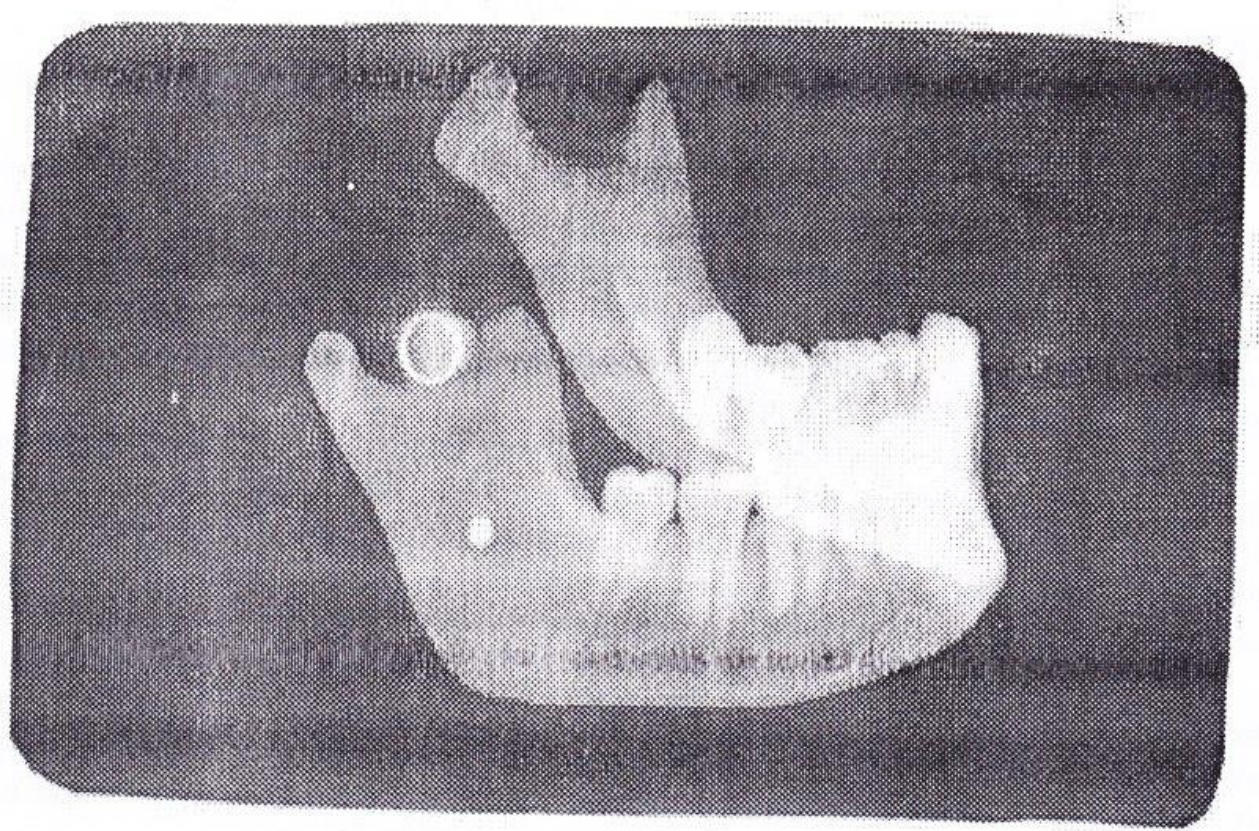

Figure (2): Lateral oblique jaw radiograph for the dry mandible with the metallic ball on the position of mandibular foramen

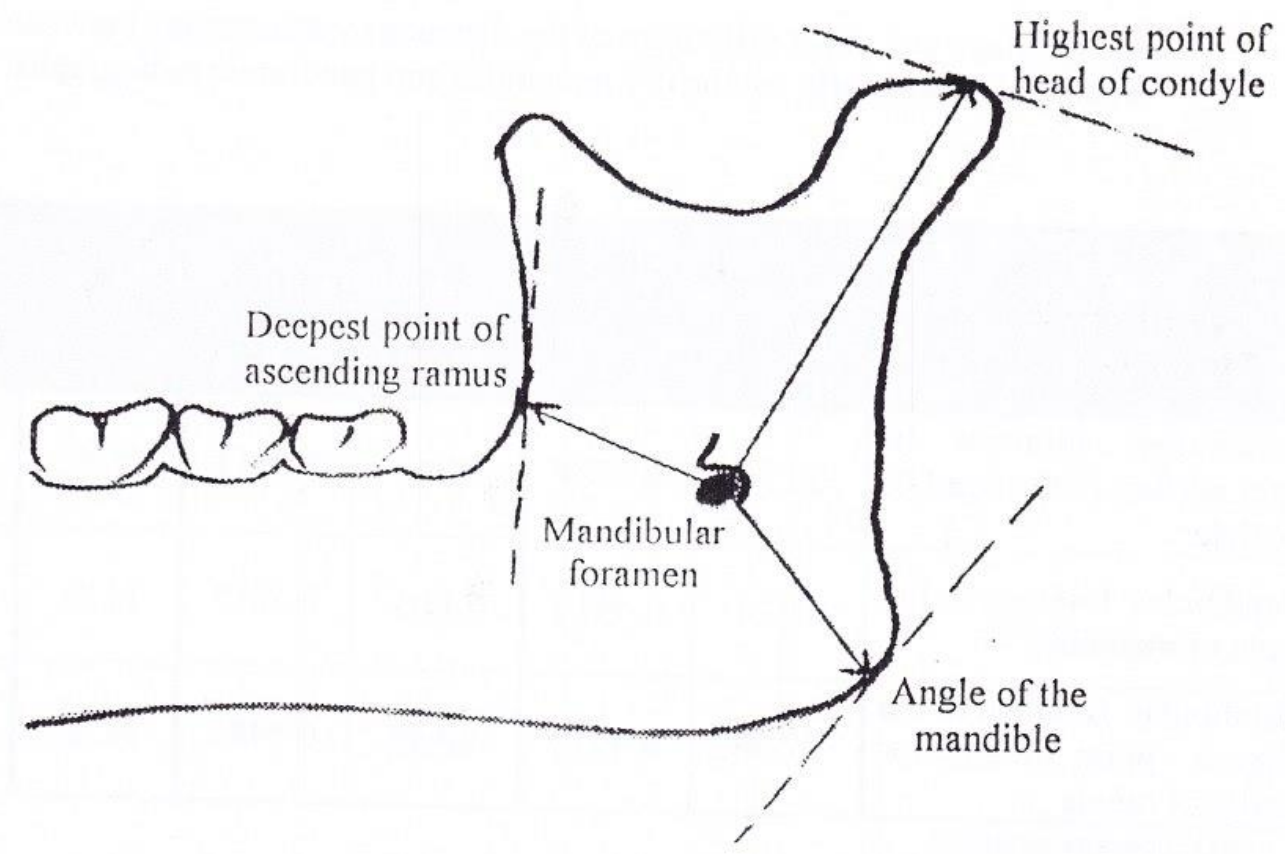

Figure (3): Diagram of the lingual view of the mandible showing the distance measured between the anatomical landmarks and the mandibular foramen 


\section{RESULTS}

The data was collected from this study will be analysed with the use of student t-test in tables (1 and 2).

The mean difference of the distance was measured between the anatomic landmarks on the normal dry mandible have been compaired with those measurements obtained from the panoramic radiographs are shown in the table (1), and the comparison between these normal measurements with the measurements are obtained from the radiographs are taken with lateral oblique jaw projection for the ramus of the mandible are shown in the table (2).

The readings are taken from those two tables (1 and 2) are shown that the mean difference between the normal measurements and those are taken from the lateral oblique jaw projections (range between $0.24-1.94 \mathrm{~mm}$ ) was less than that mean difference between all the measurements and those are taken from panoramic radiographs (range between $0.49-3.77 \mathrm{~mm}$ )

In addition to that the standard deviation of the readings from the panoramic radiographs is greater than that from the readings are taken by lateral oblique jaw projections, even there was no significant difference between all the measurements are taken from both types of radiographs when are compared with those normal anatomic landmarks measurements.

Table (1): Mean and mean difference of the distance measurements between the anatomical landmarks on the dry mandibles and panoramic radiographs

\begin{tabular}{|c|c|c|c|c|c|c|}
\hline \multirow{2}{*}{ Hilnice } & \multicolumn{2}{|c|}{ biv Niandialos } & \multicolumn{2}{|c|}{$\begin{array}{l}\text { Yimoramic: } \\
\text { Radiogratis }\end{array}$} & \multirow[t]{2}{*}{$13=0,166$} & \multirow[t]{2}{*}{ 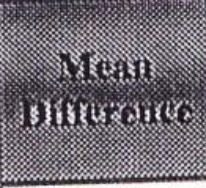 } \\
\hline & (mis) & 50 & (nin) & 90 & & \\
\hline $\begin{array}{l}\text { Mandibular foramen to } \\
\text { outer surface of the head of } \\
\text { condyle }\end{array}$ & 30.96 & 0.6924 & 31.45 & 0.8917 & N. S. & 0.49 \\
\hline $\begin{array}{l}\text { Mandibular foramen to the } \\
\text { angle of mandible }\end{array}$ & 30.24 & 0.4414 & 34.01 & 0.5817 & N. S. & 3.77 \\
\hline $\begin{array}{l}\text { Mandibular foramen to the } \\
\text { deepest point of anterior } \\
\text { border of ramus }\end{array}$ & 17.26 & 0.4012 & 20.46 & 0.5485 & N. S. & 3.20 \\
\hline
\end{tabular}

S D: Standard deviation 
Table (2): Mean and mean difference of the distance measurements between the anatomical landmarks on the dry mandibles and the lateral oblique jaw radiographs

\begin{tabular}{|c|c|c|c|c|c|c|}
\hline 1. & 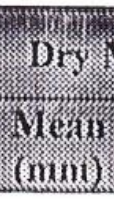 & 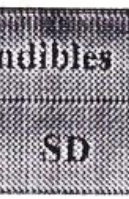 & 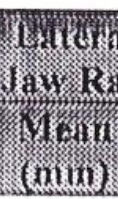 & 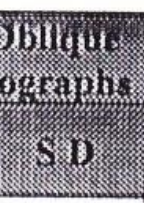 & 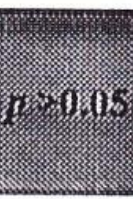 & (1) \\
\hline $\begin{array}{l}\text { Mandibular foramen to } \\
\text { outer surface of the head of } \\
\text { condyle }\end{array}$ & 30.96 & 0.6924 & 31.20 & 0.9732 & N. S. & 0.24 \\
\hline $\begin{array}{l}\text { Mandibular foramen to the } \\
\text { angle of mandible }\end{array}$ & 30.24 & 0.4414 & 32.18 & 0.4201 & N. S. & 1.94 \\
\hline $\begin{array}{l}\text { Mandibular foramen to the } \\
\text { decpest point of anterior } \\
\text { border of ramus }\end{array}$ & 17.26 & 0.4012 & 18.93 & 0.4853 & N. S. & 1.67 \\
\hline
\end{tabular}

\section{DISCUSSIONS}

The comparison between the panoramic radiograph and the lateral oblique jaw radiograph in the radiographic localization of mandibular foramen is, firstly used in this study.

As a results are shown in the tables ( 1 and 2), we find that the mean difference between the distance measurements of the normal dry mandibles and those measurements are taken from panoramic radiograph is greater than that mean difference of distance measurements with lateral oblicue jaw radiograph which may be due to the technical variations between the two types of radiographic projections results in the different resolution of the image, variation in the degree of distortion and difference in vertical and horizontal magnification ${ }^{(3)}$. So the great difference in the mean of measurements of distance between the normal dry mandible and those are taken from panoramic radiographs, this great amount of distortion in the image was related to the movement pattern, beam shape and location of focal trough ${ }^{(6)}$, but the lesser amount of distortion in the image was resulted from the lateral oblique jaw projection coming from that the beam is directed from underneath the body of the mandible, the image will suffer from distortion because of great vertical angulation ${ }^{(7)}$.

But still the image was taken with lateral oblique jaw projection is more resolution than that of panoramic radiograph this may be due to the horizontal motion involved in making a panoramic radiographs, results in slightly less resolution than was provided by the static extra oral projection.

In addition to that we find there is no significant difference between the normal anatomic landmarks measurements and the distance measurements on both panoramic and lateral oblique jaw projections, this make the radiograph is still to be the only available non invasive method for diagnosis and treatment planning of the mandible ${ }^{(8)}$. 


\section{CONCLUSION}

In conclusion we find that the presice radiographic examination of the mandible before any surgical and orthodontic treatments is very essential, and the radiography of the ramus of the mandible with lateral oblique jaw radiograph is more resoluted and accurate in the localization of the mandibular foramen, although the panoramic radiograph can be used also.

\section{REFERENCES}

1-Hetson G, Share J, Formmer J, Joseph H. Statistical evaluation of the position of the mandibular foramen. Oral Surg. 1988; 65: 32-34.

2-Reitzik M, Griffihs RR. Surgical anatomy of the ascending ramus of the mandible. Br J Oral Siurg. 1976; 14:150-155.

3-Koffe I, Ardekian L, Gelerenter H, Taicher S. Location of the mandibular foramen in panoramic radiograph. Oral Surg. 1994; 78: 662-669.

4-Williams PL, Warwick R. Gray's Anatomy. Edinburgh Churchill Livingstone. 1980; Pp: 567.

5-MacDavid WD, Tronje G, Welander U, Morris CR. Imaging characteristics of seven panoramic x-ray units: II- the image layer. Dentomaxillofac Radiol. 1985; 8: 13-19.

6-Tronje G, Welander $U$, MacDavid WD, Morris CR. Imaging characteristics of seven panoramic x-ray units: III-Projection angle. Dentomaxillofac Radiol. 1985; 8: 21-28.

7-Wrehrmann HA, Manson-Hing LR. Essential extra oral techniques. In: Dental Radiology. $5^{\text {th }}$ Edn. Mosby Co. 1981; 1'p: 135.

8-Thomas F, Gail F. Extraoral radiographic examinations. In: Current Oral and Maxillofacial Imaging. WB Saunders Co. 1996; PP: 238. 